AC 2012-5107: SENSORS AND STRUCTURES: OUTCOMES FROM A PROJECT-BASED MULTI-DISCIPLINARY GRADUATE COURSE

Prof. Elizabeth Basha, University of the Pacific

Prof. Luke S. Lee, University of the Pacific 


\title{
Sensors and Structures: Outcomes from a Project-Based MultiDisciplinary Graduate Course
}

\begin{abstract}
The goal of this paper is to assess the effectiveness of a project-based, multidisciplinary course in a small engineering program with BS and MS students. At engineering programs without doctoral degrees, limited faculty resources and small student numbers present challenges in offering graduate courses that provide hands-on learning experiences in multidisciplinary environments - the same experiences often gained in graduate level research at larger research intensive universities. Therefore, during the Spring semester of 2011, we offered a multidisciplinary course combining civil structural health monitoring (SHM) and sensor networks.
\end{abstract}

Recent research trends have tied these two topics together with an increase in the use of sensor networks for SHM and an increase in monitoring structures in sensor networks. Combining these two classes offered a unique opportunity for senior undergraduate students and graduate students to engage in multidisciplinary learning, to design and implement complicated systems spanning both fields, and to explore new research boundaries.

The Sensor Networks for Infrastructure Systems course provided a combination of depth and breadth to both undergraduates and graduates. The course consisted of two hours of lecture and three hours of laboratory time each week with content divided into three topic areas each incorporating a multi-week lab project. The final weeks of the course were devoted to large-scale final projects where student teams monitored actual structures on the university campus.

The course was assessed in comparison to two other courses offered concurrently: a graduate course in networking for ECPE/CS students and a mixed course in water resource engineering for civil engineering students. Assessment consisted of entrance and exit surveys combining Likert-scale questions, open-ended questions, and concepts maps. Additional assessment within the course included the submission of concept maps before and after each topic area.

The assessment revealed key benefits and challenges for both faculty and students. All had difficulties translating knowledge and terminology outside of their discipline. The faculty found that providing breadth to all students introduced challenges to maintaining course flow and interest while providing sufficient depth to successfully complete projects. Team management and dynamics differed greatly from traditional project classes due to specialized skill requirements (no one student could completely implement any project), challenging the faculty to determine new models and the students to learn new skills. However, students appreciated the opportunity and uniformly identified multidisciplinary projects as interesting and useful. Overall, the course identified a need for increased multidisciplinary interactions in the graduate curriculum and suggested models for how that might be achieved. 


\section{Introduction}

With increased attention toward multidisciplinary engineering education over the past decades, educators have sought to provide students with an experience that examines the full breadth of engineering problems, exposes students to diverse teams of engineers, and better reflects the needs of industry. In fact, it is well-recognized that modern engineering problems are difficult to solve within the scope of a single discipline and require individuals and teams to possess a diverse skill set and the ability to effectively integrate those skills to solve a problem ${ }^{1,2}$. Engineers who can cross the boundaries of traditional disciplines and integrate existing knowledge and create new knowledge are increasingly being sought ${ }^{1}$.

The importance of interdisciplinary collaboration is particularly relevant in graduate engineering education where research experience is paramount to development and integration of knowledge and skills. The need for interdisciplinary collaboration in engineering education and research is driven by the complexity of nature and society, problems and questions that cross disciplines, and new technologies 2,3 . However, the typical coursework based graduate degree program is often characterized by less hands-on experience, less practicality, and more in-depth theory ${ }^{4}$, a graduate research project often serves as the only bridge between theory and application.

Recently the University of the Pacific School of Engineering and Computer Science launched a Master of Science degree program in Engineering Science which emphasizes a multidisciplinary coursework based degree for graduate and blended (BS/MS) undergraduate students. While thesis and project options are available, most students opt to complete the degree solely through the coursework option. The multidisciplinary engineering degree provides students with the opportunity to integrate topics within the traditional disciplines in civil, computer, electrical, and mechanical engineering through individual courses; however, the exposure to cutting edge research is limited due to a small number of research faculty and a small graduate student population ( $<100$ students). Nonetheless, one of the necessary components of graduate education is the preparation of students to accommodate the continuous change that occurs in modern society $^{2,5}$. In addition, it is important for graduate courses to deepen existing knowledge and apply fundamental theory to current practices in the field.

In order to overcome the challenges of limited faculty resources and a small graduate student population, characteristic of a liberal arts private university, yet still provide broad experiences for our graduate and blended MS students, we planned to offer an interdisciplinary engineering course in Spring 2011 entitled "Sensor Networks for Infrastructure Systems," which combines recent developments in structural health monitoring (SHM) and the application of wireless sensor networks to assess the condition of civil infrastructure systems. Recent research trends have tied these two topics together with an increase in the use of sensor networks for SHM and an increase in monitoring structures in sensor networks. Combining these two topics offered a unique opportunity for senior undergraduate students and graduate students to engage in multidisciplinary learning and teamwork, to design and implement complicated systems spanning both fields, and to explore new research boundaries through a project based curriculum.

The goal of this paper is to assess the effectiveness of a project-based, multidisciplinary course in a small engineering program with BS and MS students. First, the paper describes the 
environment and course structure, detailing the use of laboratory based projects and the final design project in order to develop engineering and team skills in an interdisciplinary collaboration. Next, the assessment process and outcomes are outlined, followed by a quantitative analysis and a qualitative analysis. The paper concludes with some ideas for best practices and future structures of project-based, multidisciplinary courses.

\section{Environment and Course Structure}

The University of the Pacific School of Engineering and Computer Science provides three different concentrations within the Master of Science in Engineering Science degree: (1) Civil, (2) Mechanical, and (3) Electrical Engineering, Computer Engineering, and Computer Science (ECPE/CS). Each concentration requires a number of discipline-specific courses along with an advanced math course and an engineering breadth course outside of their concentration, while the existing undergraduate curriculum allows for approximately 2 courses each semester within each department.

Such restricted course options ensures significant diversity among the students, but limits preparedness for the depth required in a graduate course and diversity in course content. This often leaves students taking courses for which they do not have the background, decreasing their motivation and interest. For the professor, this requires providing significant background and preparation to ensure all students have the same foundation at the cost of delving in-depth into cutting edge areas.

Avoidance of these issues while exposing students to current research challenges suggests a need to embrace the diversity of the students and to teach multidisciplinary courses. Our approach focused on the area of structural health monitoring (SHM), which examines infrastructure such as bridges and buildings using sensor networks and signal processing. The topic requires understanding both the sensor networks performing the monitoring as well as the structure being monitored. Two professors taught the Sensor Networks for Infrastructure Systems (SNIS) course; one studies sensor networks as her research topic while the other studies structural mechanics and structural health monitoring. The course was cross-listed in their two departments: Electrical and Computer Engineering, and Civil Engineering. Final enrollment in the course had 19 students representing 6 different majors: electrical engineering, computer engineering, computer science, civil engineering, applied math, and engineering management. Table 1 shows the student breakdown. 


\begin{tabular}{|c|c|c|}
\hline Category & Description & Number of Students \\
\hline \multirow{3}{*}{ 离 } & Graduate & 9 \\
\hline & Undergraduate & 4 \\
\hline & Blended (BS/MS) & 6 \\
\hline \multirow{6}{*}{$\stackrel{\bar{\sigma}}{\pi}$} & Applied Math & 3 \\
\hline & Civil Engineering & 5 \\
\hline & Computer Engineering & 6 \\
\hline & Computer Science & 6 \\
\hline & Electrical Engineering & 4 \\
\hline & Engineering Management & 1 \\
\hline \multirow{3}{*}{ 离 } & One Major & 14 \\
\hline & Two Majors & 4 \\
\hline & Three Majors & 1 \\
\hline
\end{tabular}

Table 1: Student Properties

The course goals were to provide breadth, such that students understood the systems level aspects of SHM, and depth in the specific technical details of SHM. It also would engage students in larger scale design projects as well as multidisciplinary design projects. Prior coursework usually has a maximum of three students in a project and no multidisciplinary opportunities other than a mandatory co-op program.

In order to promote an interdisciplinary team approach to design for monitoring structures, a project-based learning approach was selected to support the process of inquiry and learning since "real world engineering projects come to fruition only through the efforts of teams focusing on real projects"5. In addition, project-based learning requires students to engage in design thinking in a systems level collaboration on teams communication in terminologies and definitions outside of their respective disciplines ${ }^{5,6}$. With this in mind, the course was divided into four components: 3 three week topic sections and 1 five week final project. Each topic section included two breadth lectures, one depth lecture where students divided based on interest and skills, one depth lab providing necessary skills to the divided students, and one breadth project where students combined their skills to solve a relevant project. Topics covered were strain gages, vibration analysis, and structural health monitoring.

To provide an example of the structure, for the first topic of strain gages, the first week consisted of a breadth lecture on strain gage theory and use along with a divided lab where students either 
learned about the Arduino microcontroller or the installation and use of strain gages. The second week also had a breadth lecture; this time it covered sensor placement and strain gage techniques. The lab introduced the strain gage project where students formed groups of 4 to determine the weight of an unknown point load on a beam using four strain gages and an Arduino with the output and calculations occurring in Matlab. The final week of the section started with split lectures discussing either accelerometers or more strain gage theory and ended with the groups testing and presenting their projects. This structure was mimicked for the other two topic areas with each also having a design project.

The final project consisted of designing a sensor network to monitor a structure on campus, building and instrumenting the structure, collecting a week of data, and performing fault detection algorithms on that data. Students divided into three teams of 6-7 to work on a bridge, a tower, or a machine lab. The nature of the projects and teams ensured that no one student could implement the entire project, but that each student needed to provide specific skills. Teams divided into three sub-teams covering the system hardware, software, and structural aspects of the project. The large size also required that students choose a leader to manage the project.

\section{Course Assessment}

Such a unique course raised questions on the utility of providing multidisciplinary opportunities at the graduate level that included project-based outcomes. The goal of the instructors was to motivate and support learning in a project based environment by assessing progress, diagnosing problems, providing feedback, and evaluating overall results ${ }^{6}$. Achieving this required incorporating the assessment into the course from the beginning. The effectiveness of interdisciplinary collaboration and learning can be based on student outcomes as cited in literature: ${ }^{1,7}$

- Students will be able to create structures that promote interdisciplinary collaboration

- Students will be able to communicate their discipline specific knowledge to collaborators

- Students will be able to describe the disciplinary approach of their collaborators

- Students will be able to identify the contributions and values of their collaborators

- Students will be able to integrate concepts and approaches from various disciplines to solve an interdisciplinary challenge.

The course started with a Likert survey to understand students' initial perceptions of multidisciplinary projects along with an open-ended question about their opinions on multidisciplinary and project-based courses. Figure 1 outlines this assessment. The same surveys were provided at the end of the course. 


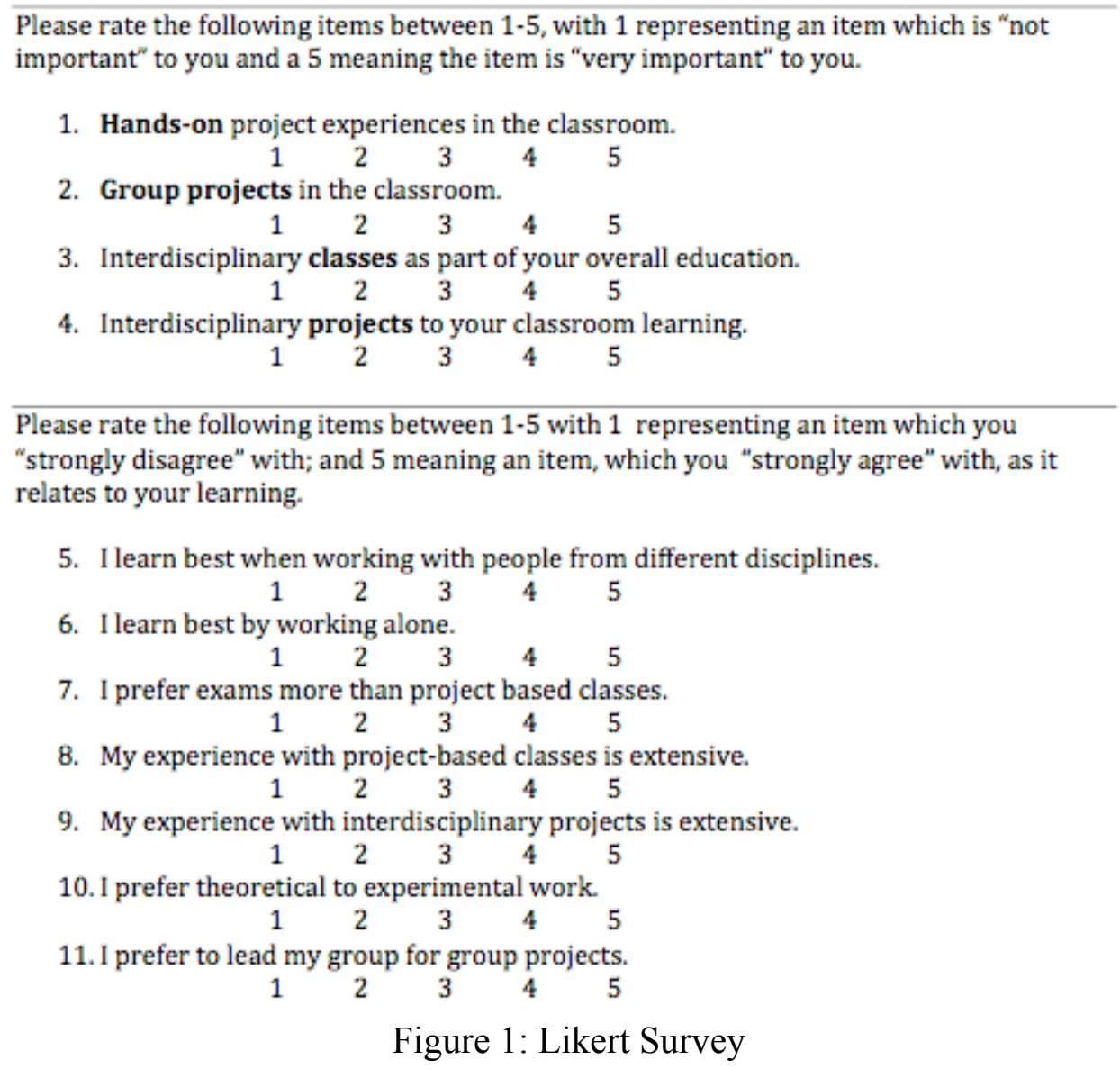

To understand the impacts of these assessments, two additional courses were surveyed at the beginning and end of the semester with the same Likert and open-ended questions. One course was a graduate course in Electrical and Computer Engineering (ECPE) titled Network Systems Architecture (NSA). This course also provided a project-based experience, but consisted of a single-discipline focus. The second course was an undergraduate course in Civil Engineering titled Water Resources Engineering (WR), which included a lab section, but no specific projects and was single-discipline. Table 2 describes the three different courses; for clarity, we define $\mathrm{BS} / \mathrm{MS}$ blended students as graduate students since they are working toward a master degree. 


\begin{tabular}{|l|l|l|l|}
\hline Course Characteristics & SNIS & NSA & WRE \\
\hline Number of Graduate Students & 15 & 9 & 5 \\
\hline Number of Undergraduate Students & 4 & 0 & 11 \\
\hline Labs? & Yes & No & Yes \\
\hline Projects? & Yes & Yes & No \\
\hline Multidiscipinary? & Yes & No & No \\
\hline Number of Students also in SNIS Class & & 6 & 0 \\
\hline
\end{tabular}

Table 2: Comparison of Three Courses

Unfortunately, there was significant overlap between the students in the SNIS course and the NSA course, which was unknown at the beginning of the semester and no other course provided a good comparator. This overlap rules out the value of that data as a comparison metric and, therefore, we removed it from our final analysis.

After performing these assessments, the results were collated. Table 3 summarizes the statistics of the SNIS course while Table 4 summarizes the WRE course.

\begin{tabular}{|c|c|c|c|c|c|c|c|c|c|c|c|}
\hline \multirow{2}{*}{ Question } & \multicolumn{2}{|c|}{ High } & \multicolumn{2}{|c|}{ Low } & \multicolumn{2}{c|}{ Median } & \multicolumn{2}{c|}{ Mean } & \multicolumn{2}{c|}{ Std Dev } & \multirow{2}{*}{$\begin{array}{c}\text { \% } \\
\text { Improvement }\end{array}$} \\
\cline { 2 - 10 } & Pre & Post & Pre & Post & Pre & Post & Pre & Post & Pre & Post & \\
\hline 1 & 5 & 5 & 2 & 3 & 5 & 5 & 4.67 & 4.67 & 0.77 & 0.69 & 88.9 \\
\hline 2 & 5 & 5 & 2 & 3 & 4 & 4 & 3.78 & 4.33 & 0.81 & 0.69 & 100 \\
\hline 3 & 5 & 5 & 2 & 2 & 4 & 4 & 3.83 & 3.67 & 0.86 & 1.08 & 61.1 \\
\hline 4 & 5 & 5 & 2 & 2 & 4 & 4 & 3.72 & 3.89 & 0.89 & 0.96 & 88.9 \\
\hline 5 & 5 & 5 & 2 & 2 & 4 & 4 & 3.56 & 3.72 & 0.70 & 0.89 & 83.3 \\
\hline 6 & 4 & 4 & 2 & 1 & 3 & 3 & 3.17 & 3.17 & 0.79 & 0.92 & 77.8 \\
\hline 7 & 4 & 4 & 1 & 1 & 2.5 & 2.5 & 2.39 & 2.39 & 1.20 & 1.20 & 77.8 \\
\hline 8 & 4 & 5 & 2 & 2 & 3 & 4 & 3.22 & 3.72 & 0.81 & 1.07 & 88.9 \\
\hline 9 & 5 & 5 & 1 & 1 & 2.5 & 3 & 2.72 & 2.89 & 1.13 & 1.41 & 66.7 \\
\hline 10 & 4 & 4 & 1 & 1 & 2.5 & 2 & 2.44 & 2.11 & 0.92 & 0.90 & 88.9 \\
\hline 11 & 5 & 5 & 1 & 1 & 3 & 4 & 3.33 & 3.50 & 0.91 & 1.20 & 83.3 \\
\hline
\end{tabular}

Table 3: SNIS Course Likert Result Statistics 


\begin{tabular}{|c|c|c|c|c|c|c|c|c|c|c|c|}
\hline \multirow{2}{*}{ Question } & \multicolumn{2}{|c|}{ High } & \multicolumn{2}{|c|}{ Low } & \multicolumn{2}{c|}{ Median } & \multicolumn{2}{c|}{ Mean } & \multicolumn{2}{c|}{ Std Dev } & \multicolumn{2}{c|}{$\begin{array}{c}\text { \% } \\
\text { Improvement }\end{array}$} \\
\cline { 2 - 10 } Pre & Post & Pre & Post & Pre & Post & Pre & Post & Pre & Post & \\
\hline 1 & 5 & 5 & 3 & 3 & 5 & 5 & 4.63 & 4.63 & 0.62 & 0.62 & 66.7 \\
\hline 2 & 5 & 5 & 2 & 2 & 4 & 4 & 3.56 & 3.88 & 0.73 & 0.89 & 61.1 \\
\hline 3 & 5 & 5 & 2 & 1 & 4 & 4 & 3.69 & 3.84 & 0.79 & 1.09 & 66.7 \\
\hline 4 & 5 & 5 & 2 & 2 & 3.5 & 4 & 3.56 & 3.66 & 0.81 & 0.94 & 55.6 \\
\hline 5 & 5 & 5 & 1 & 2 & 3 & 3 & 2.88 & 3.06 & 0.96 & 0.99 & 61.1 \\
\hline 6 & 5 & 5 & 1 & 1 & 3 & 3.5 & 3.00 & 3.00 & 1.21 & 1.32 & 55.6 \\
\hline 7 & 5 & 5 & 1 & 1 & 3 & 3 & 3.13 & 2.75 & 1.15 & 1.29 & 72.2 \\
\hline 8 & 5 & 5 & 1 & 2 & 3.5 & 4 & 3.25 & 3.63 & 1.44 & 1.02 & 55.6 \\
\hline 9 & 5 & 5 & 1 & 1 & 3 & 3 & 2.94 & 2.88 & 1.12 & 1.02 & 50.0 \\
\hline 10 & 5 & 5 & 1 & 1 & 2 & 2.5 & 2.19 & 2.63 & 1.28 & 1.09 & 44.4 \\
\hline 11 & 5 & 5 & 3 & 2 & 3.5 & 3.5 & 3.69 & 3.63 & 0.79 & 0.89 & 61.1 \\
\hline
\end{tabular}

Table 4: WRE Course Likert Result Statistics

\section{Quantitative Analysis}

Looking at this data, we can explore quantitatively the effect of the class on the students. We first examine changes in the specific questions within the course (Table 3 ) and then compare this to the Water Resource Engineering course (Table 4).

For each question, we determine the mean and standard deviation among the student response prior and after the course. Questions 1 through 4 explored students' general opinion of projects and multidisciplinary courses. These began with high values and maintained these values following the course. Specifically of interest are the changes in questions 3 and 4 . Mean student responses to interdisciplinary classes rose while responses to interdisciplinary projects fell with both seeing an increase in the standard deviation. This suggests that while students enjoyed having a class with multidisciplinary facets, the project structure of the course did not work well for them; we validate and explore this through the qualitative analysis.

Questions 5 through 10 address student perceptions of their own interests and skills regarding projects and multidisciplinary work. Here we see some expected results with students 
experiencing no change in their preference for exams or projects (projects remained preferable), an increase in experience with project-based classes, and an increase in experience with interdisciplinary projects. The latter two are important in that students did recognize skills gained through the course. Additionally, mean student preference for experimental work over theoretical work increased along with a decrease in the standard deviation around that question. Unexpectedly, student preference for working alone increased although so did the standard deviation around that question. This reflects some of the issues seen with differing student commitments and workloads; we address this further in our qualitative analysis.

The analysis of the specific questions suggests that the course did provide both skills and beneficial experiences. We additionally analyze the percent improvement per student per question where improvement depends on the specific question. For example, when examining question 1 regarding group projects, we would hope for an increase in scores. However, when examining question 7 regarding preference for exams over projects, we would hope for a decrease in scores; thereby an improvement is a reduction in a student's score. In this analysis, we see students improved in the majority of questions with the best being an appreciation for group projects and the lowest improvement seen in their appreciation for interdisciplinary classes. This indicates students did benefit from this course structure although more in regards to projects than multidisciplinary aspects.

We next consider the statistical significance of the change in question responses. For this, we compute the t-test of change in the total student responses in the pre-course questions compared to the post-course question. For our set of questions, question 2 (regarding the view of group projects) and question 8 (regarding view project-based experience level) see statistically significant changes in student perception over the course of the class with at a $p \leq 0.05$ confidence result. Both of these questions changed with an increased mean, indicating a positive change through the course. Question 10 (regarding theory over experimental) sees a statistically significant change with a $\mathrm{p} \leq 0.10$ confidence; examining the results shows that this change is a reduction in preference for theory over experimental work. Our other questions either did not show statistically significant changes or did not meet the required normal or near-normal distribution needed for this test (many had near-uniform distributions). Overall, these results indicate statistically significant improvements in students' project-based experience, but a lack of these results on the multidisciplinary side. We see similar issues when exploring students' qualitative results, which can help explain some of the mixed views of the class success in this area.

Finally, we compare the percent improvement scores to the WRE course. Given its lack of both projects and multidisciplinary experiences, we would hope to see a much greater improvement in the SNIS course compared to the WRE course with limited improvement in the WRE course. This is indeed what we see in comparing the two. WRE experiences with just labs resulted in limited improvements while the SNIS course had significant improvements across the questions.

\section{Qualitative Analysis}

In addition to quantitatively analyzing the surveys, the open-ended questions, student comments, and faculty perceptions provide an interesting qualitative analysis. We did not score their open- 
ended responses in any way, using the Likert scale responses for quantitative analysis and using open-ended responses to better understand the quantitative results along with hard to quantify issues that arose in the course.

Students almost universally in all three courses described both project-based and interdisciplinary classes as "crucial to the job market" and "providing real-life applications", which confirms statements in literature regarding the motivations behind interdisciplinary project work $^{1,5,8}$ and project-based learning ${ }^{1,6,9}$. However, those with more experience in either also identified them as an educational challenge, stating:

"They only work when people from each background all have an interest and are willing to learn a bit about the other fields"

and

"It is important that everyone participates equally on projects. Students need to clearly divide-up all work and be evaluated on the basis of their part."

After completion of the course, those in the course still held these views with additional concerns. A key concern was the project balance between the disciplines with many feeling that the Civil Engineering students did not participate as much nor have as many responsibilities as the ECPE students. This also introduced concerns about the preparedness of students to handle advanced materials with some students commenting about "the lack of maturity in the undergraduate and [new masters] students makes for an extremely bad situation" and "it was frustrating at times not knowing enough about the computer science, computer engineering and electrical components that this project demanded." A final concern dealt with the time commitment of graduate projects with some students stating that they "should be warned about the time intensive nature of the course" and "more time would be helpful" for projects.

These concerns and views were shared by the faculty teaching the course. While many students appreciated the research and interdisciplinary aspects, not all understood or recognized what this entailed for course. This led to inequalities in terms of student time commitments, which led to inequalities in the amount of work done by students and the work load balance across students. This also led to difficulties with students not recognizing that they needed to translate existing knowledge into an area outside their discipline nor accepting that they would have some level of discomfort with material from outside their discipline. Overall, the faculty found that dealing with these student skill and perception issues while providing breadth to all students introduced challenges to maintaining course flow and interest while providing sufficient depth to successfully complete projects.

Faculty also discovered challenges collaborating with each other in a new, multidisciplinary structure. Both had difficulties translating knowledge and terminology outside of their discipline as neither had background in the other's research area. This suggests that perhaps students are not the only ones requiring regular multidisciplinary experiences.

Finally, team management and dynamics differed greatly from traditional project classes due to specialized skill requirements (no one student could completely implement any project), challenging the faculty to determine new models and the students to learn new skills. Students had to identify the skill sets of individuals and divide the work effectively among each. They 
could not rely on a "star" student to save the day as each person had a unique contribution. This then required project leaders to motivate and handle conflict as opposed to single discipline projects, where all students have the same skill set. It also created a challenge for faculty in balancing individual and team grading. Without reducing the importance of completing the entire project, faculty had to determine grading policies and structures that accounted for individual contributions without over-penalizing the entire group if one person did not do his/her part. This required modifications throughout the course and remained an issue through the end of the semester.

\section{Best Practices and Future Ideas}

Given this data, we can define some best practices and ideas for future classes. The course structure needs modification in order to account for differing skill sets and topic familiarity. This would include:

- An initial remediation period to ensure students within a discipline are at the same skill and theory levels

- Providing more theoretical background via independent study (videos, literature)

To ameliorate issues with multidisciplinary projects, the project structure needs changes such as:

- Gradually increasing project sizes instead of three equally sized lab projects thereby allowing students to become more comfortable with the multidisciplinary project aspects

- Initially providing explicit roles for students in the lab projects to prepare for the final project experience

- Defining methods for the group to remove non-participating group members and redefine their project without those skills

- Designing very clear grading and peer evaluation procedures that include faculty observations (with rubrics)

Outside of course specifics, the course identified a need for increased multidisciplinary interactions in the graduate curriculum. Once students begin their discipline-specific courses, they gain different technical approaches and terminologies, but do not recognize this as all students are still in engineering (contrasting themselves with programs in humanities and sciences instead of internally). Allowing students to recognize these differences while maintaining the existing curriculum requires some creativity. Methods and models suggested by this include:

- Developing combined lab projects at sophomore and junior level courses (for example, providing a lab with both circuits and statics aspects in which students from each course participate and work together)

- Providing opportunities to combine senior design projects (even if each discipline has unique ABET criteria)

- Utilizing student competitions to provide multidisciplinary projects 


\section{Conclusions}

The goal of this paper was to assess the effectiveness of a project-based, multidisciplinary course in a small engineering program with BS and MS students. We specifically examined a graduate course in Sensor Networks for Infrastructure Systems that combined civil structural health monitoring (SHM) and sensor networks. This course provided a combination of depth and breadth through a unique structure of lectures, labs, and a comprehensive final project.

In assessing this course, we identified strong benefits for the students along with significant issues related to student skill sets, workload balance, and evaluations. While an excellent opportunity for students, they need more exposure to multidisciplinary opportunities earlier in their studies to better develop the skills necessary for success at the graduate level. Also, the course needs to provide some form of introductory period to ensure a balanced skill set within the disciplines before combining for multidisciplinary projects. Finally, projects need to increase in complexity and provide strong mechanisms for peer evaluation (up to allowing groups to remove non-working members).

Utilizing this work going forward, we hope to offer the course in Fall 2012 taking into account these lessons. We also plan to provide materials online for use in other programs and further comment from the wider academic community.

\section{Bibiliography}

1. Richter, D.M and Paretti, M.C. "Identifying Barriers to and Outcomes of Interdisciplinarity in the Engineering Classroom", European Journal of Engineering Education, 2009. 34(1): p. 29-45.

2. Committee on Facilitating Interdisciplinary Research, Facilitating Interdisciplinary Research, 2005. Washington, D.C.: National Academies Press.

3. Multi-disciplinary Design Network. "Multi-disciplinary design education in the UK: Report and recommendations", Higher Education Funding Council for England, November 2010.

4. Craig, K. and Voglewede, P. "Multidisciplinary Engineering Systems Graduate Education: Master of Engineering in Mechatronics”, in proceedings of 2010 IEEE Transforming Engineering Education: Creating Interdisciplinary Skills for Complex Global Environments, April 6-9, 2010. p. 1-14.

5. Dym, C.L., Agogino, A.M., Eris, O., Frey, D.D., and Leifer, L.J. "Engineering Design Thinking, Teaching and Learning”, Journal of Engineering Education, January 2005. P. 103-120.

6 Blumenfeld, P.C, Soloway, E., Marx, R.W., Krajcik, J.S., Guzdial, M., and Palincsar, A. "Motivating ProjectBased Learning: Sustaining the Doing, Supporting the Learning”, Educational Psychologist, 1991. 26(3-4): p. 369398.

7. Richter, D.M, Paretti, M.C., and McNair, L.D. “Teaching Interdisciplinary Collaboration: Learning Barriers and Classroom Strategies”, in proceedings of 2009 ASEE Southeast Section Conference, April 5-7, 2009. 6 pp.

8. Skates, G.W. "Interdisciplinary project working in engineering education", European Journal of Engineering Education, 2003. 28(2): p. 187-201. 
9. Barron, B.J.S., Shwartz, D.L., Zech, L., Bransford, J.D, and The Cognition and Technology Group at Vanderbilt. "Doing with Understanding: Lessons From Research on Problem- and Project-Based Learning", The Journal of The Learning Sciences, 7(3-4): p. 271-311.

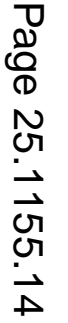

